\title{
Research on Information Literacy of Postgraduate Students Majoring in Foreign Students: A Case Study of Guangdong University of Foreign Studies
}

\author{
Shujun Chen*, \\ Guangdong University of Foreign Studies
}

*Corresponding Author: Shujun Chen, Guangdong University of Foreign Studies, China

\begin{abstract}
With the arrival of the big data age, the information literacy education of talents in colleges and universities is encountered with new challenges. In order to understand the current status and demands of the information literacy of postgraduates majoring in foreign languages in China, an information literacy investigation in Guangdong University of Foreign Studies is carried out by using the method of questionnaire statistical analysis. The survey shows that although postgraduate students majoring in foreign languages have a relatively language advantage to read original documents in various languages, their level of information literacy is still low due to the weak information awareness and the lack of ability to search and manage information. Several suggestions including advanced training lectures and embedded information literacy education are proposed at the end of this paper.
\end{abstract}

Keywords: information literacy, questionnaire investigation, postgraduate students, higher education

\section{INTRODUCTION}

With the rapid development of information technology, information-based environment has undergone fundamental changes. Information resources have become an important foundation for social, economic, and scientific development. Information literacy, which refers to "the set of integrated abilities encompassing the reflective discovery of information, the understanding of how information is produced and valued, and the use of information in creating new knowledge and participating ethically in communities of learning" (Association of College and Research Libraries, 2015), has not only become an essential ability for the talents in the 21 st century, but also the premise and foundation of knowledge innovation.

In the complex information society, the emergence of a large number of network resources has brought both new opportunities and challenges to the study and life of postgraduate students. As the reserve army in the field of scientific research, postgraduate students' level of information literacy not only determines their own innovation consciousness and scientific research ability, but also affects the talent cultivation in universities, and further relates to the construction of the national innovative talent system. Therefore, information literacy education should become an integral part and key link in postgraduate education.

Previous studies have shown that the level of information literacy of students majoring in humanities and social sciences is obviously lower than that of students majoring in science and engineering $(\mathrm{Li}$, 2013). Foreign language majors, as an important part of the humanities and social sciences, also face this problem. In recent years, many experts and scholars have expressed concern about the thinking ability of foreign language students in China, because they often emphasize imitation, recitation, and memory in language skills training. Both the learning content and the learning methods are not conducive to the cultivation and development of students' thinking ability, innovation ability, and the ability to analyze and solve problems (Wen \& Zhou, 2006). According to the author's observation, compared with those of other majors, foreign language students have the advantage of reading foreign literature, but their lack of information literacy and critical thinking ability seriously restricts the development of their scientific research ability and innovation consciousness. 
In order to have an in-depth understanding of the current situation of postgraduate students' information literacy and the demands for information literacy courses in foreign language disciplines, this paper conducts a questionnaire survey among the postgraduate students in Faculty of English Language and Culture (FELC), Guangdong University of Foreign Studies (GDUFS). GDUFS, as a key university in Guangdong province of China, has a total of 26 majors of foreign languages, the most in South China. This paper hopes to provide an important reference for faculties to set up postgraduate information literacy courses.

\section{METHODS}

In order to understand the current status of the information literacy level of postgraduate students in FELC, based on the framework for information literacy for higher education proposed by Association of College and Research Libraries (ACRL)(2015), this paper designs the questionnaire from the perspectives of information awareness, information acquisition, information management, information evaluation, and information ethics. Also, this study investigates the students' specific needs in information literacy courses. A total of 137 questionnaires are issued and 137 valid questionnaires are recovered in this survey. Among the respondents, 29.2\% are first-year postgraduate students, 34.3\% are second-year postgraduate students, and $36.5 \%$ are third-year postgraduate students and doctoral students. Male students account for $16.79 \%$ and female students for $83.21 \%$.

\section{RESULTS}

\subsection{Information Awareness}

Information awareness is one of the most basic qualities of information literacy, which refers to people's keen sense, judgement, and insight of information. It is the motivation for people to generate information demand, and then consciously seek and utilize information. Questionnaire statistics show that most of the surveyed postgraduate students are not strong in information awareness. Although $96.35 \%$ of the students think that information is very important in learning and scientific research, $3.65 \%$ of the students think little of the role of information. $45.99 \%$ of the students pay close attention to the domestic development of their discipline, while only $34.31 \%$ closely follow the development in foreign countries. $51.82 \%$ of the postgraduate students occasionally follow the domestic trend, and $59.85 \%$ of the graduate students occasionally track the development in foreign countries. However, respectively $2.19 \%$ and $5.84 \%$ of the postgraduate students report that they do not pay any attention to relevant information at home or abroad. As regards how to track the academic trends, "visiting professional websites irregularly" tops the list (89.05\%), followed by "attending academic conferences" (62.04\%), and "customizing email tracking alerts for certain databases" $(22.63 \%)$.

\subsection{Information Acquisition}

In GDUFS, there are many ways to obtain scientific research information, including paper books, periodicals, and a large number of electronic resources (e-books, databases) bought by the school library. In addition, there are plenty of free resources on the Internet. Search engines, professionalrelated forums, as well as consulting tutors and seniors are also effective ways to obtain scientific research information. The survey shows that the postgraduate students use Chinese databases (83.94\%) most, followed by foreign language databases $(78.83 \%)$ and search engines $(78.1 \%)$. Compared with the situation that only half ofthe postgraduate students majoring in science and engineering use foreign language databases (51.26\%) (Zhou et al., 2018), students majoring in foreign languages demonstrate a great advantage. The most commonly used academic information resources include journal papers $(97.08 \%)$, books $(80.29 \%)$, and academic dissertations $(76.64 \%)$, while conference literature (29.93\%) and patent and standard literature (27.01\%) are less used (Figure 1).

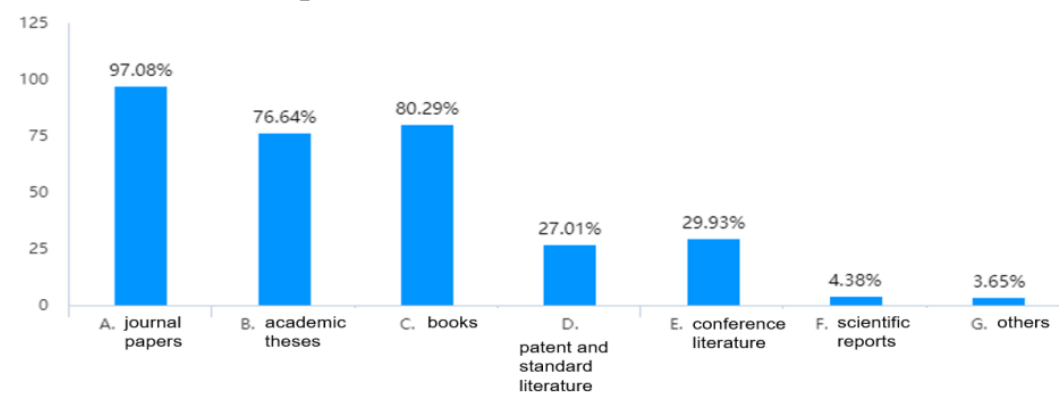

Figure1. Commonly used academic resources 
Generally speaking, the postgraduate students have more knowledge and use of Chinese databases than that of foreign language databases. All the students have used Chinese databases, but $10.95 \%$ of the respondents say that they have not used any foreign language database. In the use of Chinese databases, most students have used CNKI (99.27\%), followed by Wanfang (28.47\%), Weipu (24.09\%), and Chaoxing (23.36\%) (Figure 2). Among foreign language databases, 55.47\% have used Springer, while the uses of other databases are more scattered, including Routeledge $(31.39 \%)$, Elsevier (28.47\%), and Web of Science (27.01\%) (Figure 3).

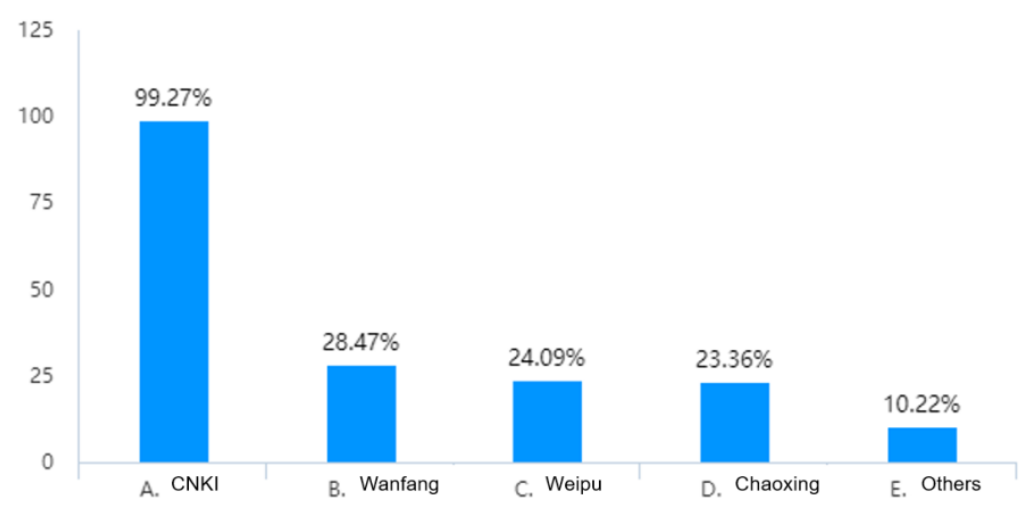

Figure2. Commonly used Chinese databases

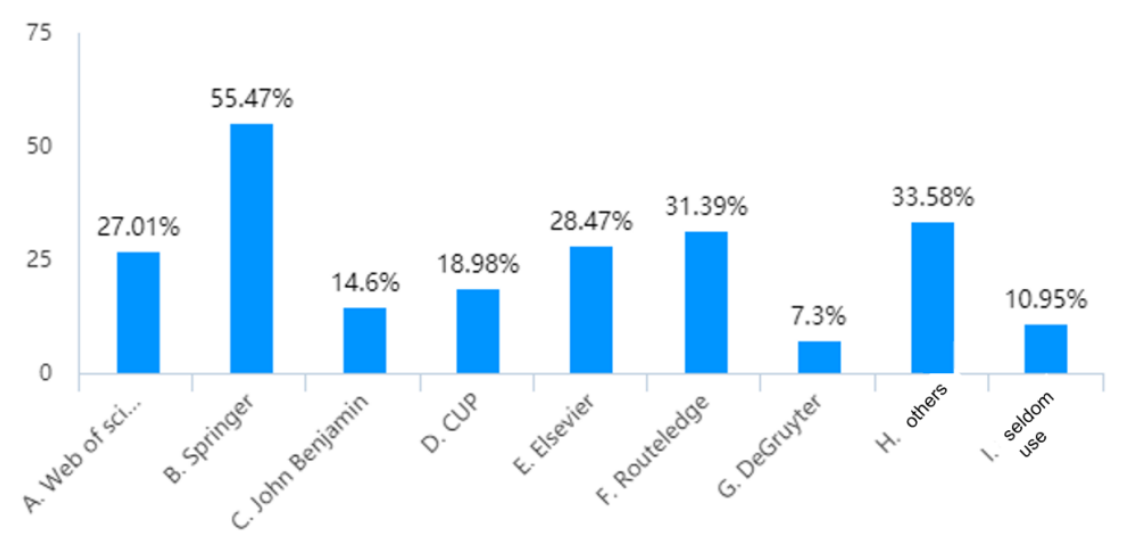

Figure3. Commonly used foreign language databases

A complete search process should include the selection of retrieval platforms, analysis of search terms, and use of search constraints. Only $43.07 \%$ of the students think that they can summarize the appropriate keywords for searching, $49.64 \%$ of the respondents intend to do so but are not confident in this aspect, and even there exist $7.3 \%$ of the students who admit they are not able to do so. As for various search strategies, $66.42 \%$ of the postgraduate students report that they have used the retrieval constraints owned by the databases, but other strategies are much less used, including truncation (17.52\%), index retrieval (10.95\%), and logical operators $(6.57 \%)$. Furthermore, $25.55 \%$ of the postgraduate students have not used any search strategy (Figure 4). The whole statistics indicate a relatively low level of search strategy application of the students.

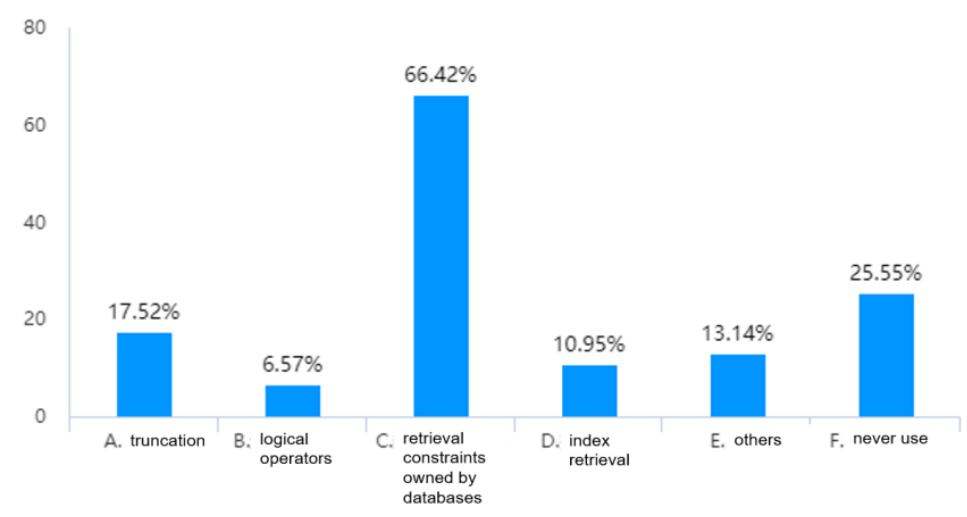

Figure4. Commonly used retrieval strategies 


\subsection{Information Management}

It is an essential information literacy ability for scientific researchers to obtain and manage the required information efficiently and effectively with the help of appropriate scientific research software. In the questionnaire survey of the postgraduate students, $39.42 \%$ of them indicate that they would make effective classification, sorting, and backup of the obtained literature materials (paper and electronic). $49.64 \%$ of them maintain that they occasionally do so. But $10.95 \%$ of the students never sort out and backup the collected documents.

With respect to various information management tools, $66.42 \%$ of the postgraduate students use Baidu Cloud disk, Dropbox, or other personal data cloud storage software. 29.2\% use personal data management software such as Youdao cloud note and Evernote. 26.28\% use reference management software like Endnote, Note Express, Mendeley, and Citavi. However, there are $16.79 \%$ of the students who have never used such information management tools.

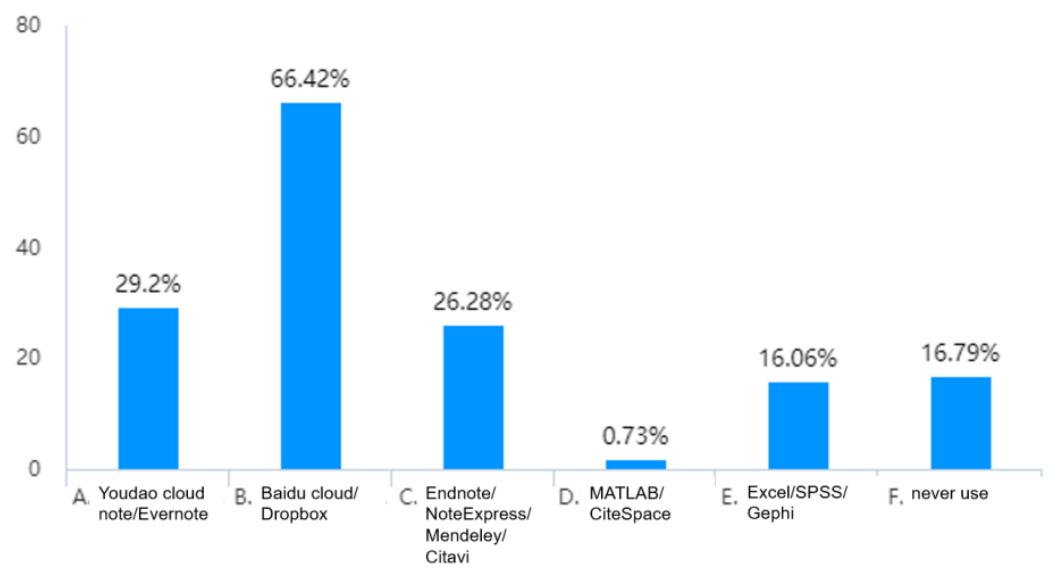

Figure5. Commonly used information management software

\subsection{Information Evaluation}

Information evaluation mainly refers to an effective judgment on the correctness, accuracy, authority, reliability, and timeliness of the obtained information and its sources, and whether it is valuable for solving the current problems. Among the answers of "how do you determine the authority and credibility of the information?", more than $85 \%$ of the students make a judgement by the influence of the institution and the author's qualifications or the number of citations. More than $40 \%$ of the students listen to the expert's comments or recommendations, and nobody does not make any discrimination and judgment.

\subsection{Information Ethics}

Information ethics refers to the sum of moral consciousness, moral norms and moral behaviors used to regulate various social relations in each link of information activities such as information collection, processing, storage, dissemination, and utilization. In scientific research activities, postgraduate students must understand the economic, legal, and social issues in the process of information use, and consciously abide by the code of ethics and relevant laws when obtaining and using information. Although $87.59 \%$ of the students believe that falsification of data, plagiarism, and other academic irregularities are very serious, still $12.41 \%$ of the students are not aware of the seriousness of the problem. As for how to cite literature, $67.88 \%$ of the postgraduate students report that they will strictly follow the relevant standards and specifications, but $32.12 \%$ of the students think that they can mark according to their own habits and will.

\subsection{Needs for Information Literacy Education}

Meanwhile, the questionnaire has also inquired about the postgraduate students' previous experience of information literacy education and their needs. There are still $32.12 \%$ of graduate students who have not received relevant education at all. 29.93\% maintain that although they have attended courses of information literacy before, the courses are not very helpful or effective. In terms of what they want to learn, $82.48 \%$ of the postgraduate students want to learn the knowledge related to academic paper writing standards, format, and submission. $73.72 \%$ of the students would like to know more about the 
use of common databases and the steps and techniques of information retrieval. More than half of the postgraduate students want to learn basic knowledge of the use of reference management tools in the courses of information literacy.

\subsection{Current Status of Information Literacy of Postgraduate Students}

The investigation shows that although postgraduate students majoring in foreign languages have a certain level of information foundation, they still have problems such as lack of the ability to search and manage information, as well asweak information ethics on the whole. First of all, although most postgraduate students realize the importance of effective retrieval, they are limited by their lack of knowledge and application ability, who cannot complete retrieval effectively. Most of the students are only satisfied with the retrieval of some relevant literature, but neglect the key links such as analyzing the retrieval results, modifying the retrieval expression, and controlling the retrieval scale. Secondly, in the aspect of information management, postgraduate students have insufficient grasp of advanced information management tools. When conducting relatively large-scale studies which involve plenty of documents or last long time, students are very likely to forget what they have read or get confused about the intricate relationship among these documents. In this case, information management tools can make great contributions to solving such problems. Finally, with respect to information ethics, some students have not realized the seriousness of falsification of data and plagiarism. When using information, postgraduate students do not fully understand the indexing rules of references and do not make normative references. It seems that postgraduate students have a strong demand for information literacy education.

\section{SUgGeSTIONS FOR INFORMATION LiteraCy Education OF POSTGRAdUATES}

\subsection{Advanced Theme Training Lecture}

The advanced thematic training of scientific research information literacy aims to acquaint students with common digital resources of the discipline, and teach them to skillfully use retrieval strategies, so that they can obtain relevant resources quickly and accurately. The lecture mainly includes several topics: accurate retrieval and acquisition of scientific research information, application of databases in scientific research, use of information management software, selection of appropriate journal sources for submission, and adherence to information ethics. Through a series of training, postgraduate students are able to master the sources of scientific research information, obtain research inspiration, specify the research direction, and find theoretical and factual evidence to support the research, thus laying a solid foundation for scientific research.

In the topic of accurate retrieval and acquisition of scientific research information, postgraduate students have access to the academic resources related to their discipline. They are guided to establish the concept of using professional resources, so that their habit of looking for academic resources only through search engines such as Baidu and Google will be changed. In addition, students will master the necessary retrieval skills, such as extracting the retrieval words through analyzing the research subject, using retrieval constraints to control the search scale, and looking for information from papers' reference lists. Reading literature review is also a fast and effective way. Most of the literature reviews at home and abroad are written by influential scholars, which can well reflect the research progress and capture the research front in this field.

With respect to the application of databases in scientific research, citation indexes such as SSCI, A\&HCI, and ESCI should be fully used by postgraduate students in their scientific research, so as to understand and grasp the latest and most authoritative academic trends and research spaces of various disciplines. Through the filtering and analysis function of the databases (such as Web of Science, Elsevier, etc.), the core literature in a certain field can be found, including the literature with high click-through rate, highly cited literature, and peer-recommended literature. What's more, students learn to use the alert function of different databases and Google Reader to track information efficiently. Various information customization approaches can provide students with information from multiple data sources according to users' specific limitations on information and specified cycles (daily, weekly and monthly), thus saving their time of browsing each database one by one and improving the efficiency of scientific research.

As for the session which teaches the use of information management software, students learn to use 
information management software to categorize papers from different sources and manage them online. The information management software also has the powerful function of automatically generating the required reference format and inserting references while writing, which will play a very good auxiliary role in the process of paper writing. In addition, by means of sharing files and research progress in the software, research team members can collaborate with each other seamlessly, and jointly advance the project.

As regards the topic of selection of appropriate journal sources for submission, postgraduate students first get familiarized with the important journals in their discipline. Namely they have a general understanding of these journals' impact factors, journal review cycle, journal record tendency, journal quality, and other information. Furthermore, with the help of the analysis function of databases (such as Web of Science), the ranking status of journals in a certain field can be analyzed for reference when students are submitting papers. Finally, through the analysis of their own research and the journals which are collected during the process of topic selection and article writing, such as comparing the impact factors and the acceptance tendency of these journals, students are able to find the right journals to make a submission.

In regard to information ethics, students learn to follow the code of information ethics and make rational use of information, including avoiding malicious downloadin the use of database query information; abiding by the laws, regulations, and institutional policies related to access and use of information resources; and declaring the source of the cited information, and consistently using an appropriate citation format when writing a journal paper or dissertation.

\subsection{Integrated Information Literacy Education}

Previous works have shown that students who take the courses with integrated information literacy instruction provided by librarians, are more likely to have academic success (Lowe et al., 2015; Gaha et al., 2018). Therefore, in addition to the above advanced information literacy lectures, it has become an important trend whether at home or abroad to integrate information literacy education into the daily teaching and practice of various professional disciplines, as well as scientific research, by paying attention to strengthening the cooperation between libraries and teaching departments. For instance, the library and the scientific research projects can collaborate to implement the integrated education of information literacy. Specifically, the library provides scientific research information support services for the project team members. According to the actual situation of postgraduate students in the projects, information literacy teachers explain the methods and skills of information retrieval for them, and guide them to conduct literature review of thesis proposals, as well as offer help during the process of writing and submission of scientific papers, such as how to use information management software and how to choose journals for submission.

\section{CONCLUSION}

Although this paper only explores the status of the information literacy of postgraduate students majoring in English at GDUFS, through the field investigation of information literacy education in other foreign language colleges and universities, we have found that the problems in information literacy education in Chinese colleges and universities are universal. Compared with the United States and other developed countries, there is still a big gap in both theory construction and curriculum setting. Due to the weak information awareness and the lack of information acquisition and management ability, even though postgraduate students majoring in foreign languages have the language advantage to read the original documents in various languages rather than the translated texts, their level of information literacy is still low.

The lack of theoretical research makes it hard for us to view information literacy education from a strategic perspective. The incomplete education evaluation system makes it difficult for us to establish the teaching objectives of information literacy education, and arouse the attention of administrative departments. The rapid pace of social development forces us to change the current situation. Specifically, it is high time for us to strengthen information literacy education, make information literacy education become the foundation of comprehensive quality education, and thus accelerate the training of innovative talents.

In terms of the cultivation of postgraduate students' information literacy ability, it is also necessary to 
put forward practical plans to improve their information literacy based on the actual situation and needs of each school and team, and make timely adjustments according to the highlighted new problems in practical operation, so as to improve their information literacy in a real sense.

\section{ACKNOWLEDGEMENT}

This work has been supported by Graduate Education Innovation Funding Project of Guangdong University of Foreign Studies [19GWYJSCX-11].

\section{REFERENCES}

[1] Association of College and Research Libraries. (2015). Framework for information literacy for higher education. Retrieved from http://www.ala.org/acrl/standards/ilframe work.

[2] Li, D. (2013). Xinxi nengli quntijian chayi yu gaoxiao tushuguan xinxi sushi jiaoyu gaijin yanjiu (Research on intergroup differences in information literacy and the improvement of information literacy education in university library). Hebei keji tuyuan (Hebei Library Journal of Science and Technology), 26 (3), 39-42.

[3] Wen, Q. \& Zhou, Y. (2006). Pingshu waiyu zhuanye xuesheng siwei nengli de fazhan (Comments on the development of thinking ability of foreign language majors). Waiyu xuekan (Foreign Language Research), 5, 76-80.

[4] Zhou, B., Zhou, M., \&Liu, D. (2018). Gaoxiao yanjiusheng xinxi suyang ji jiaoyu duice: yi Nanjing ligong daxue weili (Research on the information literacy of postgraduate students and the education countermeasures: a case study of Nanjing University of Science and Technology). Xinshiji tushuguan (New Century Library), 11, 14-19.

[5] Lowe,M.S., Booth, C., Stone, S.M., \& Tagge, N. (2015). Impacting information literacy learning in firstyear seminars: A rubric-based evaluation. Portal: Libraries and the Academy, (15) 3, 489-512.

[6] Gaha, U., Hinnefeld, S., \&Pellegrino, C. The academic Library's contribution to student success: Library instruction and GPA. College \& Research Libraries, 79 (6), 737-746.

\section{AUTHORS' BIOGRAPHY}

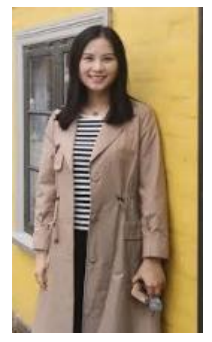

Shujun Chen, $\mathrm{PhD}$ candidate, is a research assistant of language and education at Guangdong University of Foreign Studies, China.

Citation: Shujun Chen "Research on Information Literacy of Postgraduate Students Majoring in Foreign Students: A Case Study of Guangdong University of Foreign Studies" International Journal of Humanities Social Sciences and Education (IJHSSE), vol 7, no. 11, 2020, pp. 01-07. doi: https://doi.org/10.20431/23490381.0711001 .

Copyright: (0) 2020 Authors. This is an open-access article distributed under the terms of the Creative Commons Attribution License, which permits unrestricted use, distribution, and reproduction in any medium, provided the original author and source are credited. 